\title{
sciendo
}

Research Article

(C) 2019 Wat Ploysri and Chantana Viriyavejakul. This is an open access article licensed under the Creative Commons Attribution-NonCommercial-NoDerivs License (http://creativecommons.org/licenses/by-nc-nd/3.0/).

\section{Development of Professional Competency for Printing Quality Control Personnel Using Training System via Edmodo}

\author{
Wat Ploysri \\ Ph.D., Candidate in Industrial Education, \\ Faculty of Industrial Education and Technology, \\ King Mongkut's Institute of Technology \\ Ladkrabang (KMITL), Thailand \\ Chantana Viriyavejakul \\ Ph.D., Associate. Prof., \\ Faculty of Industrial Education and Technology, \\ King Mongkut's Institute of Technology \\ Ladkrabang (KMITL), Thailand
}

Doi: $10.2478 / \mathrm{mjss}-2019-0046$

\begin{abstract}
This study aimed to solving problems in providing printing quality control personnel to Thai printing industry. The problems which are mainly concerned including: (1) the lack of competency and ability in authentic performance as well as (2) the lack of capacity in following the professional standard. Therefore, the study employs Edmodo to facilitate the training system. The research procedures included these following processes: (1) reviewing literature, (2) Exploring and evaluating the needs, (3) developing the training system prototype, (4) Evaluating the conceptual framework developed, (5) Drafting the training package through Edmodo, (6) evaluating and Implementing the training system, and (7) Taking the result into improving. The result elucidated that the developed PQC-Training system, after being applied into creating the training package by using the Edmodo website and application, could effectively promote the trainees' professional competency that was in accordance to requirements of organizations in Thai printing industry.
\end{abstract}

Keywords: Edmodo, Printing quality control, Professional development, Printing industrial, Training system

\section{Introduction}

Printing quality control is an integral system of maintaining strict standards in publishing production (i.e., printing preparation, printing process, equipment or machine used and printing material) as well as in maintaining a quality of the color pigment flowing throughout the publishing process, keeping a constant standard from the proof sheet to the print sheet (Helmut, 2001). This is evidently resulted in quality publishing which entails customers' satisfaction (BCQ Group, 2015) as well as rereceiving the service or word of mouth. According to the importance of printing quality control to publishing production, checking publishing production by using the printing quality control (e.g., ISO 12647-2 standard) can promote producing more efficient publishing, reduce amounts of printing ink and paper used as well as saving time in the printing preparation (Prepressure, 2013). Hence, if the printing quality control personnel have essential professional skills, it will conduce to the successful completion of its work (Daniel, 2006).

The labor situation in the publishing industry around the world nowadays can be briefly 
explained as following: (1) In European countries, due to the technology advancement, the higher demand on industrial-skilled labors as well as the higher age of formerly-employed labors, the personnel who can skillfully handle the new-technological tasks are required (European Commission, 2018). (2) In Oregon, United States, labors in different departments in publishing industry are supposed to decline, and the working labors are elderly; therefore, personnel replacement is necessary (Rooney, 2017). This is consistent with the labor overview of the country that the increase of labor retirement in the country entails reducing the number of laborers. Thus, a professional training for new personnel in enhancing their competency in order to equal to the former labors is emphasized (John, 2016). (3) In Japan, there is a skilled labor shortage resulting in the establishment of confederation to promote the new generation to perceive the publishing industry as well as support skill development (Andy, 2018).

In Thailand, the Thai Publishing Industry has a severe labor problem in that many laborers are still unqualified, and lack new-technology perception (Wiroon, 2009) which corresponds to the solution in the 12th national economic and social development plan that highlights on solving problems about having professionalism that is not consistent with the needs of the labor market. Therefore, , the government is promoting professional training to respond the labor market demands by (1) developing a performance-based curriculum that meets the need of organizations and (2) providing electronic media which promotes convenient and easily-accessible training (Office of the national economic and social development board, 2017). Due to the fact that the industry could not be interrupted with a total training program, which would hinder the present work load, a new system had to be introduced that would have maximum effectiveness.

Edmodo was chosen for its ability to effect change in an industry without disturbing the present work systems of the industry staff. With its references, the researchers would like to investigate this solution to overcome the Thai publishing industry problems of unqualified laborers by utilizing functions of Edmodo in order to help the participated printing-quality-control personnel acquire appropriate techniques and approaches as well as become aware of the importance of printing quality control.

\section{Research Purpose}

1) Develop the professional competency training system for printing quality control personnel by utilizing Edmodo, without disruption of the work industry.

2) Draft the prototype of professional competency training system for printing quality control personnel as well as construct the training package for maximum effectiveness.

3) Examine the learning achievement of the sample who received the professional competency training system from Edmodo.

\section{Literature Review}

\subsection{Training System}

A training system involves a series of coursework which links personnel, resources and techniques together to enhance the professional competency of a trainee to correspond with the required standard. People who participate in a training system include workers/trainees, trainers, curriculum developers, training evaluators, educational executives, logistic managers, training-media-design experts as well as the heads of each organization. As a quick glance, the interests and goals related to training system of a person in the particular career are not similar to another person from another and different career. The materials used in a training system normally are made up of training media and documents as well as specific equipment and tools in evaluating the training involved. The techniques employed in a training system are a training need analysis, training design method, training assistant design method, training efficiency analysis, logistic analysis and Value analysis (Robert \& Michael, 1988). Online training system is a convenient channel in representing the web-based training courses on various platforms, such as desktop, laptop as well as smart phone on every operating system which helps the trainees can anywhere and anytime 
access to the training course (ProProfs, 2017).

\subsection{Edmodo}

Edmodo refers to the social network or smartphone application for instructors, students and school. The Edmodo has security systems as well as can create the appropriate environment for learning. Additionally, the users can communicate, collaborate, exchange the educational contents as well as easily access to assignments, grades and group news (Enzuber, 2011). The benefits of Edmodo are described as following (Walsh, 2013):

1) It can use several platforms in the form of application on tablet and smartphone or web browser without extra expenses needed.

2) It presents a non-threatening environment in learning for learners since the Edmodo has a special qualification on security systems, such as inviting the classmates to join a group by using security password as well as learners' parents being able join the group. In the case of any young students involved.

3) It can facilitate the teaching and learning for each activity, such as preparing contents of instructor or posting and discussing contents online of learner.

4) If learners would like to know something in question or the assignment, they can immediately login to search for the information as the program is always accessible, no matter what place or time.

5) It is a social networking platform that allows teachers and students to interact, collaborate as well as sharing learning contents even though they are in different places and not interrupt any work processes.

\subsection{Edmodo for Training}

The Edmodo which was utilized to enhance professional competency of the printing quality control personnel had both social-network and Learning Management System (LMS) characteristics (Andreia, 2018; Matt, 2017) that could be explained as following:

1) Keeping learners motivated: Edmodo could promote the feeling of being an owner as well as participating. It helped the trainees can conveniently follow the contents or the missed topics. In addition, it could also provide the opportunity for the trainers to consult their friends on what they missed in class by only logging in the server.

2) Providing individual feedback: The benefits of online channel may provide a higher chance for the speaker to personally deliver suggestions regarding the results and answers of what the trainees wondered. Besides, the speaker was also abled to add activities which could suitably contribute the trainees' competency.

3) Encouraging collaboration amongst learners: This channel could stimulate the communicating during the training as well as generating opinions and discussion. Furthermore, owing to the result of the case study or finding occurred during the training, it could help planning, solving existing problems as well as correctly and safely following trainee partners. (Hussain et. al., 2018)

Another crucial point of using Edmodo is that during the training via both website and application did not interfere to the regular work or their colleagues which entailed the labor deficiency during the training. Besides, it also helped reducing time in preparing the curriculum as well as the organization expense in case of personnel training (Bakanova et. al., 2018).

\section{Methodology}

The researchers conducted the applied research based on the research and development conceptual framework proposed by Brahmawong (2012) and Seels and Glasgow (1998). It could be explained as presented in the Table 1. 
Table 1: Research methodology

\author{
Research Process \\ 1. Reviewing literature and relevant studies in Literature and relevant studies \\ order to be background knowledge of studying - Development of training
the printing quality control personnel. \\ - Competency development \\ - Printing quality control \\ - Edmodo
}

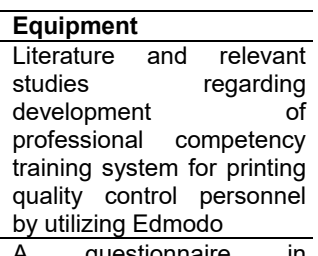

2. Exploring and evaluating the needs toward Managers or equivalent to the manager position $A$ questionnaire in
the training system required by the who were working in publishing industry investigating organizations using the questionnaire to survey organizations in Bangkok area. A stratified satisfaction, necessity and an opinion on the characteristics, necessities random sampling method was used for selecting need toward the training and needs of the training system. sample. The sample included 360 participants system.

This process offered the researchers know that could be classified into 120 heads of about the current conditions and requirements prepress work, 120 heads of press work and 120 in utilizing Edmodo into the training system and heads of post-press work (Ploysri, Viriyavejakul, professional needs which could be proceeded \& Brahmawong, 2016, p. 96-109) to developing the conceptual framework prototype.
3. Developing the prototype.
1. Literature and relevant studies

The training system prototype comprised of 2 . Information from exploring and evaluating the components including its name of the prototype, needs toward the training system required principles and rationale, objectives, details of the prototype, resources used as well as benefits.

4. Evaluating the conceptual framework The experts who were responsible for evaluating A five-likert scale developed by experts.

the conceptual framework were 10 publishing questionnaire in evaluating technology experts consisting scholars, the conceptual framework. representatives who used the training system as well as the managers of organizations which require training system application. The data was collected by using focus group discussion method.
5. Drafting the training package.
1. Literature and relevant studies
An evaluation form in
The researchers construct the training 2. Information from Exploring and evaluating the approving the conceptual package which comprised of the conceptual needs toward the training system required framework, tool design, how to daft the training 3. the conceptual framework developed and package and present its contents, documents evaluated by experts used in training, efficiency and achievement test as well as how to evaluate the information. After framework prototype in order to draft the professional competency training system for printing quality control personnel. completing the daft of the training package, the data of the package was uploaded to the Edmodo website.

6. Evaluating and Implementing the training package. The sub-processes were explained as following:

1. Evaluating the training package on its 6 printing and educational technology experts. contents as well as training techniques.

2. Implementing the training package which Trainees were 20 printing industry students in passed the efficiency test to the 20 students SSRU who enrolled in the academic year 2017, package for experts. who had never registered the printing quality and had never register the printing quality control - The training package control and comparing their test scores between course. They were chosen by using simple - A multiple-choice test pre training and post training in order to random sampling from the total population with 78 (four choices in each examine the learning achievement.

3. Investigating the satisfaction after the 20 trainees who received the training by using sample received the training.

- Evaluation form regarding the content and question) as a pretestposttest in examining the learning achievement. - A five-likert scale questionnaire in surveying the satisfaction towards the professional competency training system.

7. Taking the result into improving the training 20 trainees who received the training by using Evaluation form regarding system. training package via Edmodo the utilization 


\section{Results}

The results of the study could be separated into 3 sections including:

\subsection{Result of Developing the Professional Competency Training System for Printing Quality Personnel}

After investigating the needs of the training system required by the organizations, the results were applied into developing a conceptual framework. After that, the developed conceptual framework was evaluated by the experts. The result of the evaluation found that the overview of appropriateness of the system was at the highest level, and the details were explained in: the conceptual framework (Ploysri, Viriyavejakul, \& Brahmawong, 2017), by the following paragraphs:

System components: conforming to the study and its findings, the system of Printing Quality Control-Training (PQC-Training) contained 4 components including input, process, output, and feedback. The details were explained in figure 1 :

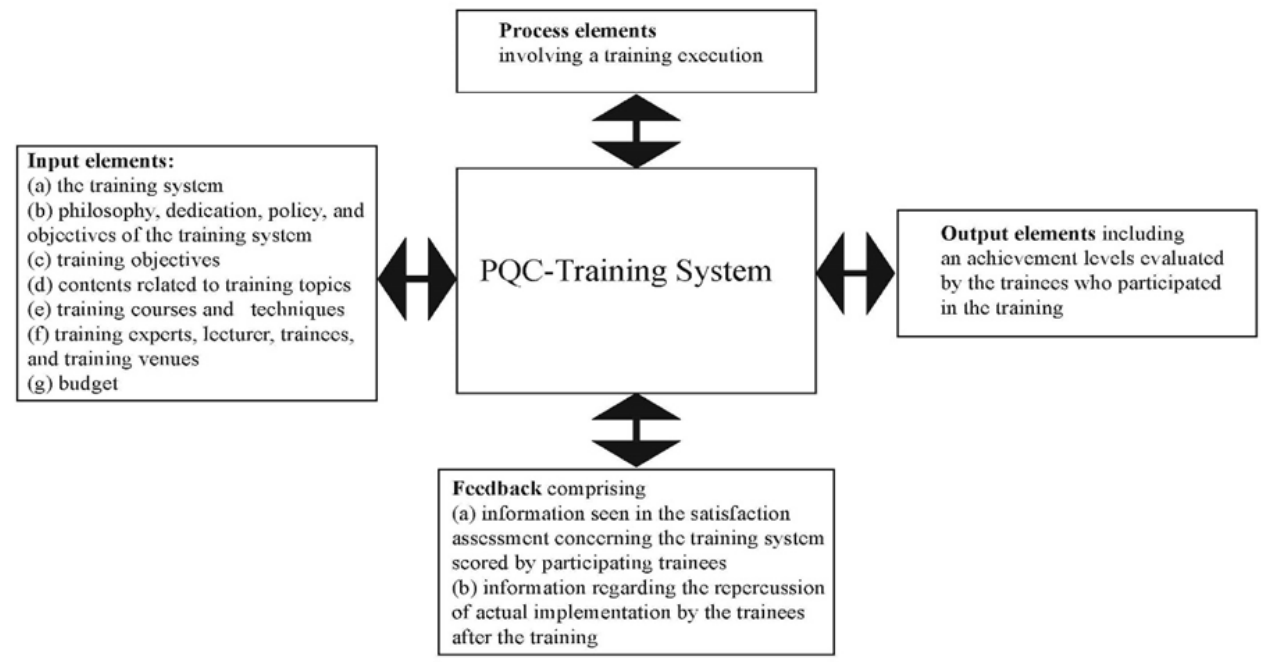

Figure 1: System components of PQC-Training system

The processes of PQC-Training system could be explained as following:

Process 1: Analysis of problems and needs - the existing difficulties and professional demands of printing quality personnel towards the training system based on the businessorganization requirement were analyzed in order to be information for the system design.

Process 2: Establishment of training plan and training objectives - the vision, philosophy, mission statement and goals were identified in order to accomplish training-system purposes.

Process 3: Training development - the training procedures, operation as well as other resources were developed by considering the trainees' accessibility on knowledge, skills and attitudes which were consistent to the training-system requirements. The result of this process was the training package.

Process 4: Training pilot - the developed training package was tested in the authentic situation. In piloting, the readiness of trainees, pre-training procedures, training procedures, posttraining procedures as well as learning-achievement evaluation were analyzed.

Process 5: Assessment and follow-up on the training system - the piloted training system was assessed. Besides, there was a follow-up on utilizing the training system of trainees.

Process 6: Improvement and maintenance of the training system - this process related to improving and maintaining the system (e.g., modernizing the contents of the training system or motivating users to use the training system). 


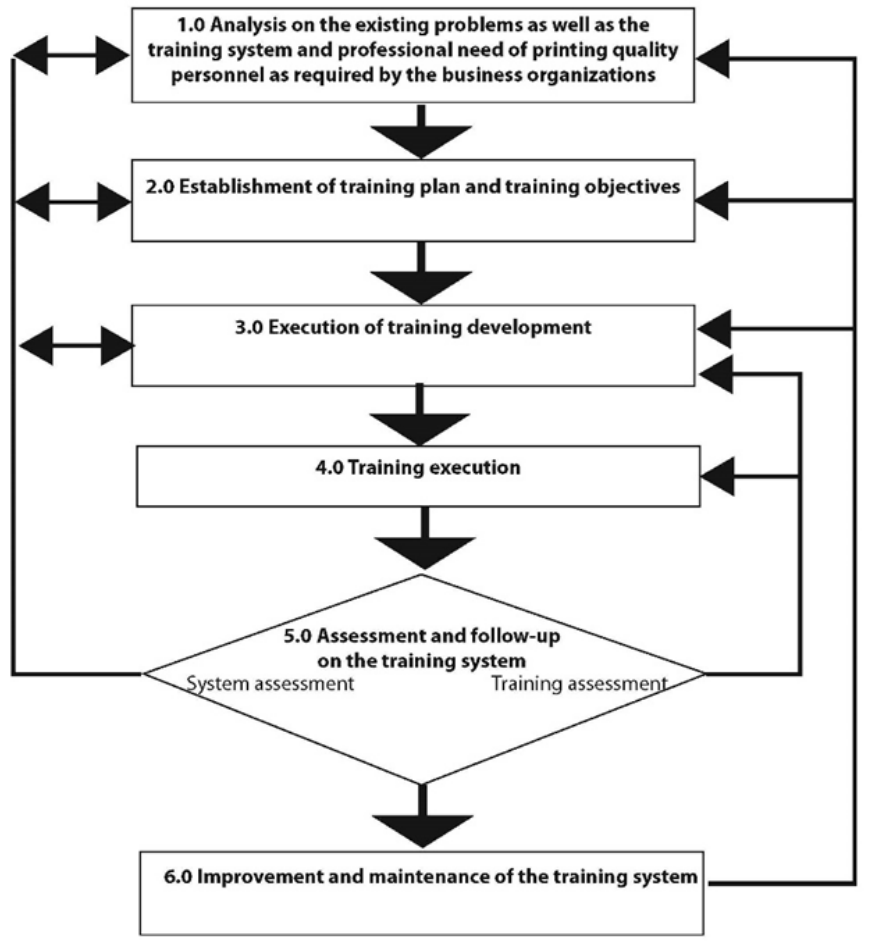

Figure 2: The processes required in the training $P Q C$-Training system

\subsection{Results of Drafting the Training System and Constructing the Training Package}

\subsubsection{The Results of drafting the training system.}

After the conceptual framework was developed by researchers as well as evaluated and adjusted by 10 experts who were involved with the system, the researchers drafted the training system and brought it to approve by the 10 experts in order to check whether the conceptual framework could be used in a real situation. The result of the approval was that the training system had a high level of effectiveness, and it could be easily and practically implemented.

\subsubsection{The Result of constructing the training package.}

After the conceptual framework passed the evaluation and usability ascertainment, the researchers brought the developed training system to construct the training package.

1) The training package was a series of training steps or phases developed by using a conceptual framework. It was a competency-based curriculum utilizing the Edmodo website and application from which the e-books, illustrations and videos were provided in order to respond to the participants' demand in accessing the training at any time or place. The use of Edmodo in supporting the PQC-Training system to train the trainees to have higher professional competency was consistent to the objectives. In addition, the strength of Edmodo which was a social-network site could stimulate the communicating during the training as well as generating opinions and discussion. Furthermore, owing to the result of the case study or finding occurred during the training, it could solve the problems existing during the training as well as correctly and safely follow trainee partners. Furthermore, it also helps the trainees immediately consult their partners and the speaker on what they had wondered. Clearly, these would not occur in the traditional training. 


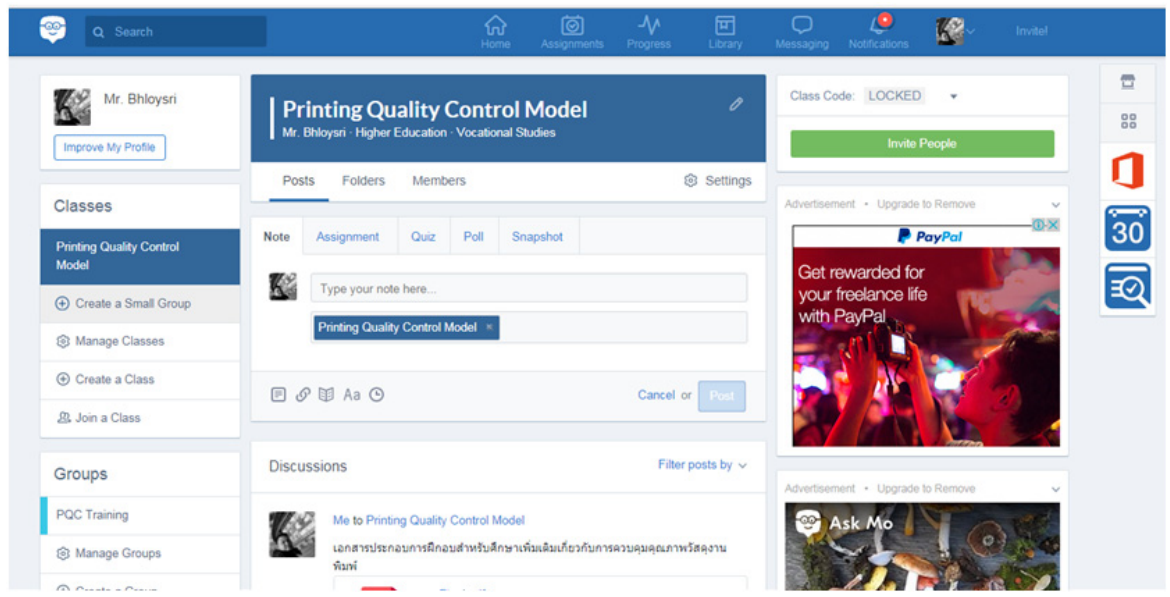

Figure 3: The display of the training package

2) The training package was constructed by applying the conceptual framework, and able to be adjusted according to the experts' suggestion until it reached the highest level of contents and presentation approved by the six printing and educational technology experts. Moreover, it was piloted in order to explore the efficiencies until it could be effectively conducted in the real training.

3) The content of the training comprised of information about offset printing quality control theory on publishing. It was separated into 3 major sections including prepress quality control, press material quality control, and press quality control.

\subsection{Results of Examining the Learning Achievement of the Trainees in the Training System}

The learning achievement of the sample including 20 trainees was examined by using one-group pretest-posttest design (Donald \& Julian, 1963). The procedures involved making and giving the pre-training test, conducting training by using the training package, and giving the post-training test respectively. After that, the results of the pre-posttest were analyzed into statistical data by using ttest dependent as shown in the Table 2.

Table 2: The result of learning achievement of the participating trainees

\begin{tabular}{lccccc}
\hline Result & Mean & S.D. & t & df & Sig. \\
\cline { 1 - 3 } Pre training & 11.30 & 3.570 & \multirow{2}{*}{$13.869^{* *}$} & \multirow{2}{*}{19} & \multirow{2}{*}{.000} \\
\hline Post training & 32.75 & 4.983 & & & \\
\hline
\end{tabular}

Table 2 shows the result of the data analysis with the t-test dependent; the $t$ value was $13.869^{*}$ and the Sig. value was .000 which could be described that the participating trainees were succeed in receiving the training system as evidenced by the learning achievement in post training was higher than the pre training having the significance level at .01. Regarding conducting the survey on the trainees' satisfaction towards the training package which was developed from the training system, the result showed that there was the highest level of the satisfaction.

\section{Conclusion and Discussion}

After gathering all information regarding necessary characteristics which the training system should have as well as the desirable professional performance of printing quality control, the researchers developed the system under the name "PQC-Training system". The training system that was developed had a high level of evaluation result as evaluated by the 10 experts who were involved with the system. After applying the training system into the development of the training package in order to use in training via Edmodo website and application, the outcome was evaluated by the printing 
technology and educational technology experts, and the findings of the evaluation indicated the high level. Thus, it could be used in the authentic situation. Due to the study of the current conditions, characteristics of performing tasks, characteristics, necessity and needs of the training system, professional competency of printing quality control personnel, the processes in evaluating the conceptual framework of the training system as well as the participation of administrators and users in operating the training adapted from the framework of Pawlowski (2007), the researchers could perceive the actual needs and problems. Moreover, the 7-steps model of Brahmawong (2012) also support the researchers to better understand the hindrances as well as solutions of the system before conducting the real training. This could ensure that the training system can be efficiently utilized creating quality training courses, and could be also used for professional training. In other words, the development of the training system had provided very positive and effectual results.

Regarding the authentic training program to explore learning achievement of the trainees, the comparison of the test scores between pre-training and post-training, by using t-test dependents, it was revealed that the learning achievement of the post-training was significantly higher than that of the pre-training with .01 , meaning that the participating trainees changed their behaviors after being trained by utilizing the Edmodo System. Consequently, the trainees displayed the highest level of satisfaction towards the training system. The result of participating trainees' behavior change after being trained using Edmodo demonstrated that the ineffectiveness of the traditional training (i.e., the trainees forgot what they had learn, and were neither unable to review it nor asked the speaker about what they wondered after training) could be solved by employing the training system which applied Edmodo as a mediator, and entail the higher professional competency of the trainees. It presented in the form of the scores of the questionnaire conducted after training as well as observing the trainees' real-situation performance (Dea, 2015).

The reason why the training system had a large number of participating trainees corresponded with Tharin (1998) that the training manager should specify qualifications of the participating trainees and it could help the training manager easily manipulate and understand the curriculum contents and importance as well as benefit the training. This caused the sample's learning achievement in post training to be significantly higher that the pre training with as evident by the Sig. with .01 .

The satisfaction towards the training package developed from the training system from the website and Edmodo application of the trainees who passed the training was at the highest level, a result of the similarity between the Edmodo and Facebook. The result of satisfaction in the current research was consistent with Tugce Berkan and Goknur (2018) that the satisfaction in using Edmodo was analogous to the social network called Facebook which is an advantage to encourage the users to create their online communities and communications. This allowed all participating trainees ability to comment on different parts of the presentation as well as simultaneously having easy access to all comments. It was conforming to Menzies, Petrie, and Zarb (2017) that the result of using Facebook strategy for higher education had a positive effect due to the face-to-face collaborative learning system. Moreover, the result also corresponded with Cooke (2017) and Boa, Wattanatorn, and Tagong (2018) in that applying the social media, such as Facebook and Twitter in higher education enabled and enhanced teaching and promoted better learning as it provided students with more opportunities to participate classroom activities that improved students' attitudes towards on-the-job learning experience and created more learning motivation. It was maybe because of the number of materials used in the online course. In other words, the more the materials are used, the higher level of learners' satisfaction is reached. This corresponded to Arzu (2016) that there were many kinds of materials used.

\section{Recommendation}

The environment of a training system should be appropriately adjusted to each situation in order to be to be consistent with the difference of trainees and be most effective without interfering with normal operations. In other words, grouping trainees can be divided into 3 levels depending on their competency, such as high-competency, moderate-competency and low-competency levels. Having these 3 levels in an organization or industry makes the training system more appropriate for an industry like the Thai Printing Industry which is in full swing rather than trying other systems that might not be as effective or disturb ongoing work. 


\section{Acknowledgements}

The researchers would like to express his gratitude to National Research council of Thailand for helping us in terms of financial assistance.

\section{References}

Andreia, Z. (2018). What is Edmodo?. [Online] Available: https://www.whatiselt.com/single-post/2018/01/28/What-is-Edmodo (March 29, 2018)

Andy, T. (2018). Label forum shows Japan's strength. [Online] Available: http://www.labelsandlabeling.com/features/latest/labelforum-shows-japan\%E2\%80\%99s-strength (March 29, 2018)

Arzu, D.T. (2016). Examination of University Students' Level of Satisfaction and Readiness for E-Courses and the Relationship between Them. European Journal of Contemporary Education, 15(1), 7-23.

Bakanova, A.P et al. (2018). The concept of personalized e-learning with the use of mobile applications based on ontologies. Revista Espacios. 39(17), 36.

BCQ Group. (2015). BCQ group awarded BPIF ISO12647-2 colour management certification. [Online] Available: http://bcqgroup.com/iso12647-2-certification. (March 29, 2018)

Brahmawong, C. (2012). Research and Development R\&D. [Online] Available: https://www.youtube.com/watch?v=mEICBNeecc0 (May 15, 2016)

Boa, E.A., Wattanatorn, A., \& Tagong, K. (2018). The development and validation of the Blended Socratic Method of Teaching (BSMT): An instructional model to enhance critical thinking skills of undergraduate business students. Kasetsart Journal of Social Sciences, 39(1), 81-89.

Cooke, S. (2017). Social teaching: Student perspectives on the inclusion of social media in higher education. Education and Information Technologies, 22(1), 255-269.

Daniel, S. (2006). Innovation Zen. Knowledge, Competencies and Attitudes. [Online] Available: http://innovationzen.com/blog/2006/09/25/knowledge-competencies-and-attitudes (March 15, 2018)

Dea, P. (2015). Prezı. How does Edmodo provide learning benefits?. [Online] Available: https://prezi.com/g2m-dtzung6q/how-doesedmodo-provide-learning-benefits (March 21, 2018)

Donald, T. C., \& Julian C. S. (1963). Experimental and quasi-experimental designs for Research. Boston: Houghton Mifflin.

Enzuber. (2011). EDMODO. [Online] Available: https://edmodoteacherhub.wikispaces.com/file/view/Exec-Summary-Edmodo.pdf (March 15, 2016)

European Commission. (2018). European Commission. Printing industry. [Online] Available: https://ec.europa.eu/growth/sectors/raw-materials/industries/forest-based/printing_en_en (March 15, 2018)

Helmut, K. (2001). Handbook of Print Media. Berlin: Heidelberg.

Hussain, I, Cakir, O, \& Candeger, U. (2018). Social Media as a Learning Technology for University Students. International Journal of Instruction, 11(2), $281-295$.

John, B. (2016). The Printing Industry Employee Demographics Time Bomb. [Online] Available: https://americanprinter.com/050416pgsf-print-industry-demographics- time-bomb-ampr (March 15, 2018)

Matt, P. (2017). What is a Learning Management System (LMS)?. [Online] Available: https://www.docebo.com/blog/what-is-learningmanagement-system (March 21, 2018)

Menzies, R., Petrie, K., \& Zarb, M. (2017). A case study of Facebook use: Outlining a multi-layer strategy for higher education. Education and Information Technologies, 22 (1), 39-53.

Office of the National Economic and Social Development Board. (2017). Plan of the National Economic and Social Development Vol.12 (2017-2020). [Online] Available: http://www.nesdb.go.th/ewt_dl_link.php?nid=6422 (March 15, 2018)

Pawlowski, J. M. (2007). The quality adaptation model: adaptation and adoption of the quality standard ISO/IEC 19796-1 for learning, education, and training. Educational Technology \& Society, 10(2), 3-16.

Ploysri, W., Viriyavejakul, C., \& Brahmawong, C. (2017). Conceptual framework development of social media based training system designed for printing quality control personnel. Proceedings of the 9th international conference on humanities and social, 2537. http://fs.libarts.psu.ac.th/research/conference/proceedings- 9/Proceedings-9.pdf

Ploysri, W., Viriyavejakul, C., \& Brahmawong, C. (2016). An analysis of social-media training needs for Thai printing enterprises. Asian International Journal of Social Sciences, 16(2), 96 - 109.

Prepressure. (2013). ISO 12647. [Online] Available: https://www.prepressure.com/printing-dictionary/i/iso-12647 (March 21, 2018)

ProProfs. (2017). What is an Online Training System. [Online] Available: https://www.proprofs.com/c/lms/what-is-online-trainingsystem (March 15, 2018)

Robert T. H., \& Michael J. S. (1988). Simulation fidelity in training system design: bridging the gap between reality and training. New York: Springer-Verlag.

Rooney, B. (2017). Technology Reduces Employment in the Printing Industry. [Online] Available: https://www.qualityinfo.org//technology-reduces-employment-in-the-printing-industry (March 15, 2018)

Seels, B. \& Glasgow, Z. (1998). Making Instructional Design Decisions. (2nd ed.). New Jersey: Merrill.

Tharin M. (1998). A Development of a Vocational Training System for Faculty Members of Rajamangala Institute of Technology. [Online] Available: http://www.thaithesis.org/detail.php?id=58816 (March 15, 2016)

Tugce A., Berkan C., \& Goknur K. (2018). A qualitative investigation of student perceptions of game elements in a gamified course. Computers in Human Behavior. 78, 235 - 254.

Walsh, K. (2013). 10 Reasons Why Edmodo is an Excellent (and Hugely Popular) Digital Learning Platform. [Online] Available: http://www.emergingedtech.com/2013/12/10-reasons-why-edmodo-is-a-excellent-and-hugely-popular-digital-learningplatform (March 15, 2016)

Wiroon, S. et al. (2009). General knowledge of printing, unit 15. (2nd ed.). Nonthaburi: Sukhothai Thammathirat Open University. 